\title{
Accidental cold-related injury leading to hospitalization in northern Sweden: an eight-year retrospective analysis
}

\author{
Helge Brändström*, Göran Johansson', Gordon G Giesbrecht ${ }^{2}$, Karl-Axel Ängquist ${ }^{3}$ and Michael F Haney ${ }^{1}$
}

\begin{abstract}
Background: Cold injuries are rare but important causes of hospitalization. We aimed to identify the magnitude of cold injury hospitalization, and assess causes, associated factors and treatment routines in a subarctic region.

Methods: In this retrospective analysis of hospital records from the 4 northernmost counties in Sweden, cases from 2000-2007 were identified from the hospital registry by diagnosis codes for accidental hypothermia, frostbite, and cold-water drowning. Results were analyzed for pre-hospital site events, clinical events in-hospital, and complications observed with mild (temperature $\left.34.9-32^{\circ} \mathrm{C}\right)$, moderate $\left(31.9-28^{\circ} \mathrm{C}\right)$ and severe $\left(<28^{\circ} \mathrm{C}\right)$, hypothermia as well as for frostbite and cold-water drowning.
\end{abstract}

Results: From the 362 cases, average annual incidences for hypothermia, frostbite, and cold-water drowning were estimated to be 3.4/100 000, 1.5/100 000, and 0.8/100 000 inhabitants, respectively. Annual frequencies for hypothermia hospitalizations increased by approximately 3 cases/year during the study period. Twenty percent of the hypothermia cases were mild, $40 \%$ moderate, and $24 \%$ severe. For $12 \%$, the lowest documented core temperature was $35^{\circ} \mathrm{C}$ or higher, for $4 \%$ there was no temperature documented. Body core temperature was seldom measured in pre-hospital locations. Of 362 cold injury admissions, 17 (5\%) died in hospital related to their injuries. Associated co-factors and co-morbidities included ethanol consumption, dementia, and psychiatric diagnosis.

Conclusions: The incidence of accidental hypothermia seems to be increasing in this studied sub-arctic region. Likely associated factors are recognized (ethanol intake, dementia, and psychiatric diagnosis).

Keywords: Accidental hypothermia, Frostbite, Body temperature, Rewarming, Cold-water Drowning

\section{Background}

Accidental cold injuries, including hypothermia, frostbite and cold-water drowning, are important causes of injury and hospitalization in subarctic regions [1-5]. Interest in these types of accidental injuries has increased after several cold-weather mass casualty events, [6,7] where immersion and submersion in cold water has led to lifethreatening hypothermia and cold-water drowning. Incidences and outcomes of cold injury have been reported for some regions [8] or nations [9] and in military populations $[10,11]$. Accidental cold-related injury is a potentially life-threatening condition that can lead to significant

\footnotetext{
* Correspondence: helge.brandstrom@vll.se

'Department of Surgical and Perioperative Sciences, Anesthesia and Intensive Care Medicine, Faculty of Medicine, Umeå University, S-901 85 Umeå, Sweden

Full list of author information is available at the end of the article
}

morbidity and life-long effects. Populations in cold climate regions, without proper safeguards and preparation when outdoors, are always at risk for cold injury. Based on previously published material, it is recognized that the occurrence of cold-related injury is often multifactorial [12-16]. Factors contributing to fatal hypothermia have been recently described [17]. It is not known if cold injury hospitalization and in-hospital survival is increasing over time, since presumably there is steady progress in prevention and treatment.

The aim of this study was to identify the incidence of cold-related patient injuries, and describe the rescueactivities, pre- and in-hospital treatment, and injury panorama in Northern Sweden during an 8-year study period from 2000 to 2007 . Additionally, we wanted to estimate the association between cold-related injuries 
and ethanol/drug use, psychiatric illness or dementia, and accidents.

\section{Methods}

\section{Identification of the cohort}

This retrospective study was conducted with approval from the Regional Ethical Review Board in Umeå, Sweden. Data was collected from patient records for those admitted to the 12 hospitals in northern Sweden, population approximately 900000 (the northern four County Council health care districts) for eight years, from 2000 to 2007. Subjects were identified in the hospitals' patient administrative system using the International Classification of Diseases, version 10 (ICD-10) [18]. The codes for hypothermia (T68), frostbite (T33.0-T35.7) and drowning (T75.1) were used as search criteria. We identified coldwater drowning based on drowning site water temperature $<20^{\circ} \mathrm{C}$, $[19,20]$ from municipality-reported lake/river temperatures at the time of the accident.

\section{Data collection from hospital records}

The diagnosis of hypothermia was based on the history and setting, clinical signs and symptoms as interpreted by the hospital physician in charge of the patient, together with measurement of core temperature. The diagnosis of frostbite was based on the history or clinical setting, together with clinical signs either of being frostbitten and already thawed, or being frostbitten at admission. The diagnosis of drowning was based on history at admission by the attending physician.

Patient records were reviewed by the co-authors and dedicated research nurses, and a structured collection form was used to record data (data collection sheet in English provided as Additional file 1). Data was categorized into four main periods. First, at the accident scene: data on environmental conditions, clothing worn and type of exposure were recorded. Second, during prehospital transport: data on type(s) and duration(s) of transport(s), treatment and environmental conditions during transport were recorded. Third, during hospital admission: data on patient treatment, core temperature and cardio-respiratory status, location and severity of frostbite, medical history, alcohol/drug use/abuse, injury, laboratory findings from the initial injury period as well as discharge information and duration of hospital stay was recorded. Fourth, follow-up information: data on medical status, hypothermia or cold injury sequelae were recorded.

The site of temperature measurement was obtained when available. Mild hypothermia was defined as core temperature from $34.9-32^{\circ} \mathrm{C}$. Moderate hypothermia was defined as core body temperature from $31.9-28^{\circ} \mathrm{C}$. Severe hypothermia was defined as core temperature $<28^{\circ} \mathrm{C}$ $[1,21,22]$. Frostbite injuries were described by location and/or severity (i.e., superficial or deep). The diagnosis of psychiatric disease, dementia or somatic disease was based on the medical journal report of a previously established diagnosis or medical information from the patient's family. Drowning was defined as those admitted alive with a history of submersion and who were given the hospitalization diagnosis T 75 according to ICD 10.

\section{Statistical methods}

Concerning statistical analysis, univariate linear regression was performed for analysis of annual incidences from year to year, and $R^{2}$ values were presented. A test for a single population proportions was performed to identify differences in frequencies in a single population (Z test, or paired difference test) [23]. A Pearson Chi Squared test was used to test for differences in distribution of frequencies. P-values less than 0.05 were considered significant in these tests.

\section{Results}

\section{General incidences}

There were 362 total cold-related injury patient admissions identified by hospital ICD 10 diagnosis codes during this period (2000-2007). This included 244 hypothermia, 105 frostbite, and 56 outdoor cold-water drowning cases. Twenty-two drownings were in very cold water $\left(<6^{\circ} \mathrm{C}\right.$, winter accident or fallen through ice) (3). This corresponded to an estimation of average regional annual incidence of hospitalization during this period for hypothermia of 3.4 per 100000 residents, along with 1.5 frostbite cases $/ 100000$, and 0.8 drowning cases per 100000 . Co-occurrence of hypothermia, frostbite and drowning was noted for some cases (Figure 1). The main finding was that there was a year-to-year increase in the incidence of hypothermia $(\mathrm{p}=0.01)$ (Figure 2$)$. Frostbite and coldwater drowning incidence did not change over the 8-year period of study. Cold injury events occurred more frequently in men $(254,70 \%)$ vs. women $(108,30 \%$; p < $0.003)$ (Table 1). Time of year and location have an association with cold injury occurrence (Figure 3 and Table 2).

For the 244 hypothermia cases, core temperatures were seldom reported for pre-hospital locations $(n=30)$, but almost always at hospital $(\mathrm{n}=233)$. The largest proportion of hospital patients had mild hypothermia (63\%), with similar smaller proportions moderate $(23 \%)$ or severe (19\%). Temperatures were not noted in 11 (4\%) patient journals despite the registered hospital admission diagnosis of hypothermia. Temperature measurement site was not noted in the hospital record for most patients $(\mathrm{n}=$ $225,92 \%$ ), and only a few were documented as rectal (5\%) or tympanic membrane (15\%) measurements (no esophageal temperature measurements were noted).

Hypothermia temperature categories and dysrhythmias are shown in Table 3, and only a few malignant 


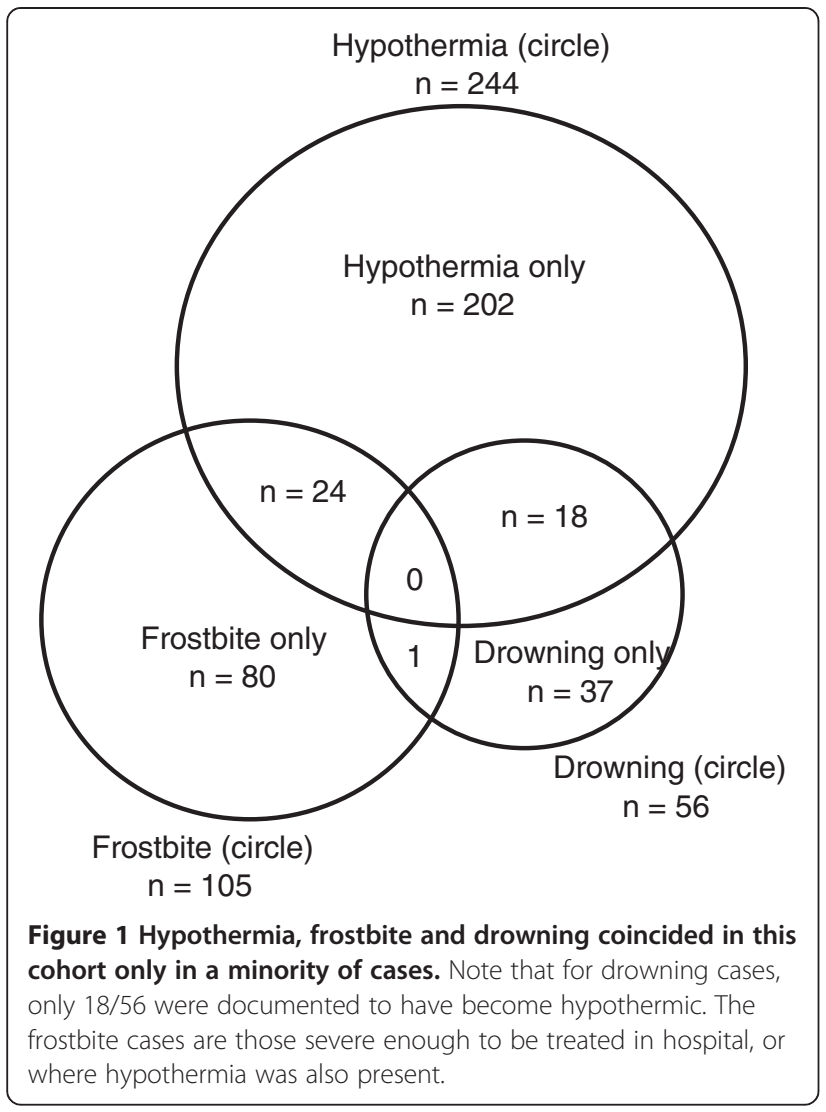

dysrhythmias were reported, mostly for severe hypothermia patients. It is notable that an electrocardiogram was recorded and interpreted in only $43 \%$ of the hypothermia cases. Pre-injury activities for hypothermia, frostbite, and drowning were noted only sporadically in the medical records (Table 4). Laboratory findings at admission for hypothermia patients showed that $\mathrm{pH}$, platelets, and potassium were distributed over a broad range (results not shown), with no clear patterns or trends discernible.

\section{Hospital management, rewarming}

Once taken into hospital, active rewarming with a forcedair warming system was most commonly used. Often more than one warming method was employed at the same time (Table 5).

\section{Frostbite}

Deep frostbite was noted mostly on hands and feet in this hospitalized cohort (Table 6). Frostbite victims reported that they received their injuries with, among other activities, walking and snowmobiling. Associated factors included ethanol consumption (Table 4).

\section{Complications}

For the total group of 362 admitted for cold injury, 16 (4\%) died in-hospital at some point; all deaths but one were admitted with hypothermia. For hypothermia specifically, the in-hospital mortality was 6\% (15/244). Cause of death for $15 / 16$ was cardiac arrest, and 1/16 stroke. One patient admitted to hospital with mild hypothermia, died after many days in hospital related to chronic cardiovascular illness.

Of the total number that were admitted with frostbite $(n=105)$, amputation of the injured aspect resulted for a small number $(\mathrm{n}=11,10 \%)$, providing an average annual incidence for frostbite-related amputation of 0.15/100 000/year. Long-term physical impairment and

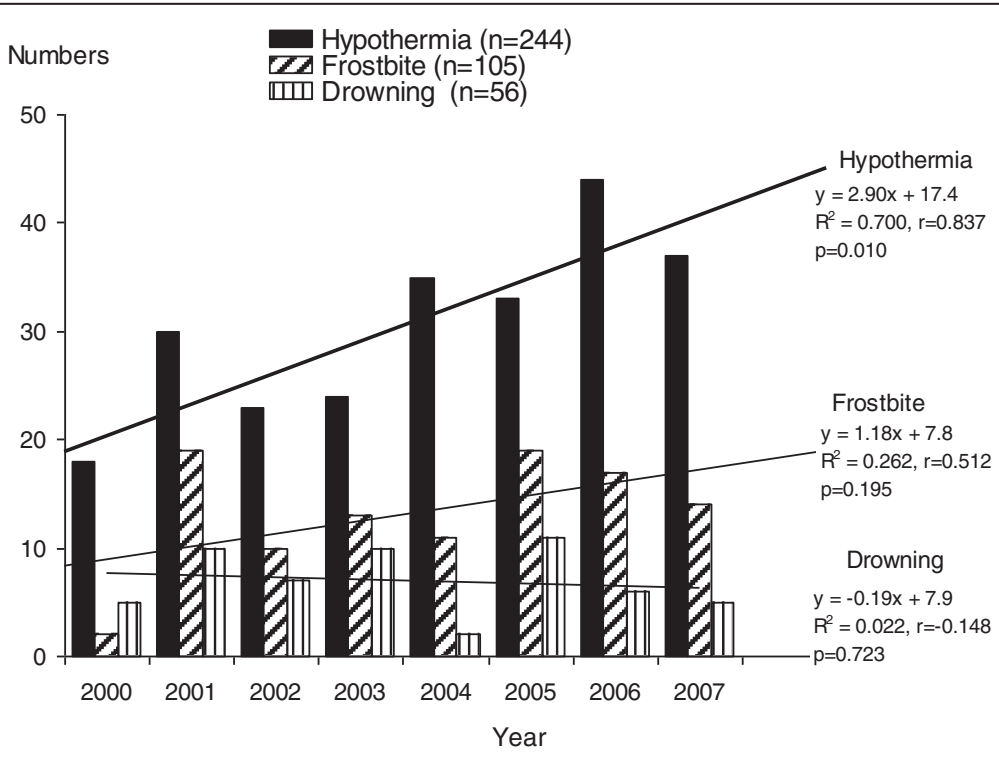

Figure 2 Annual cold injury events are shown during the study period. Linear regression analysis indicates that there was an increase in hypothermia annual frequency during this period, though not for the other diagnosis groups. 
Table 1 Incidence (\% of total) and median age (range) in each type of cold injury

\begin{tabular}{lccc}
\hline & $\begin{array}{c}\text { Male } \\
\mathbf{n}=\end{array}$ & $\begin{array}{c}\text { Female } \\
\mathbf{n}=\end{array}$ & $\begin{array}{c}\text { All } \\
\mathbf{n}=\end{array}$ \\
\hline Hypothermia all & $164(67 \%)^{*}$ & $80(33 \%)$ & 244 \\
Mild $\left(34.9-32^{\circ} \mathrm{C}\right)$ & $112(73 \%)$ & $42(27 \%)$ & 154 \\
Moderate $\left(28.0-31.9^{\circ} \mathrm{C}\right)$ & $31(56 \%)$ & $24(44 \%)$ & 55 \\
Severe $\left(<28.0^{\circ} \mathrm{C}\right)$ & $17(59 \%)$ & $12(41 \%)$ & 29 \\
Missing data & $4(67 \%)$ & $2(33 \%)$ & 6 \\
Frostbite & $82(78 \%)^{*}$ & $23(22 \%)$ & 105 \\
Cold water drowning & $41(73 \%)^{*}$ & $15(27 \%)$ & 56 \\
Age median (min-max) & & & \\
Hypothermia all & $57(8-94)$ & $72(4-97)$ & $60(4-97)$ \\
$\quad$ Mild $\left(34.9-32^{\circ} \mathrm{C}\right)$ & $56(8-94)$ & $77(10-95)$ & $59(8-95)$ \\
$\quad$ Moderate $\left(28.0-31.9^{\circ} \mathrm{C}\right)$ & $59(29-87)$ & $77(4-94)$ & $68(4-97)$ \\
$\quad$ Severe $\left(<28.0^{\circ} \mathrm{C}\right)$ & $66(15-83)$ & $69(46-90)$ & $66(15-90)$ \\
Frostbite & $50(2-94)$ & $55(2-98)$ & $52(2-98)$ \\
Cold water drowning & $42(1-83)$ & $11(1-67)$ & $36(1-83)$ \\
\hline
\end{tabular}

(*indicates larger proportion by $\mathrm{Z}$ test, $\mathrm{p}<0.05)$.

musculoskeletal dysfunction as a result of frostbite injury was noted for $2 / 105$ patients. Impaired sensorium after frostbite injury was noted for $3 / 105$ patients. Cold intolerance or chronic pain was noted for 3/105 patients.

\section{Discussion}

The main finding is an estimated recent incidence (3.4/ 100 000) for hypothermia with hospitalization which is higher than previously reported $(1.1 / 100000)$ from a similar region [9]. The findings for frostbite were confirmatory concerning annual incidence [24-26]. In our cohort, there were more male victims, while female victims had a more advanced age. The age and gender results could support the idea that older females may be more affected while having chronic illness, and that younger males may be more often victims of exposure due to daytime outdoor activities. Frostbite occurred at a higher rate among males, and could be related to more common outdoor occupational or leisure-time activities [26]. In-hospital mortality for hypothermia (6\%) in this cohort was relatively low compared to a Dutch report [9].

Another notable finding was the increase in hypothermia incidence over the study period. This may be due to attitudes where community members under-appreciate the risks, and overestimate their own abilities and equipment. A second factor may be an increased number of community members at advanced age and with chronic illness, who are more vulnerable for cold injury. A possible confounding factor may be bias related to changes in physician awareness and increased reporting. There has been an active educational process in the region (and nationally, in Sweden) concerning cold injury during the study period, sponsored by the Swedish National Board of Health and Welfare [5].

A small number of the hypothermia cases occurred indoors, [17] and typically these occur where there is an open door, or in an indoor site which is not heated or poorly heated. An explanation may be that there are demographic changes, more elderly and medically debilitated in the population living at home, and often alone, which may explain a higher relative risk in the regional population $[27,28]$. Without earlier reports of coldrelated injury incidences from the same region, it is not

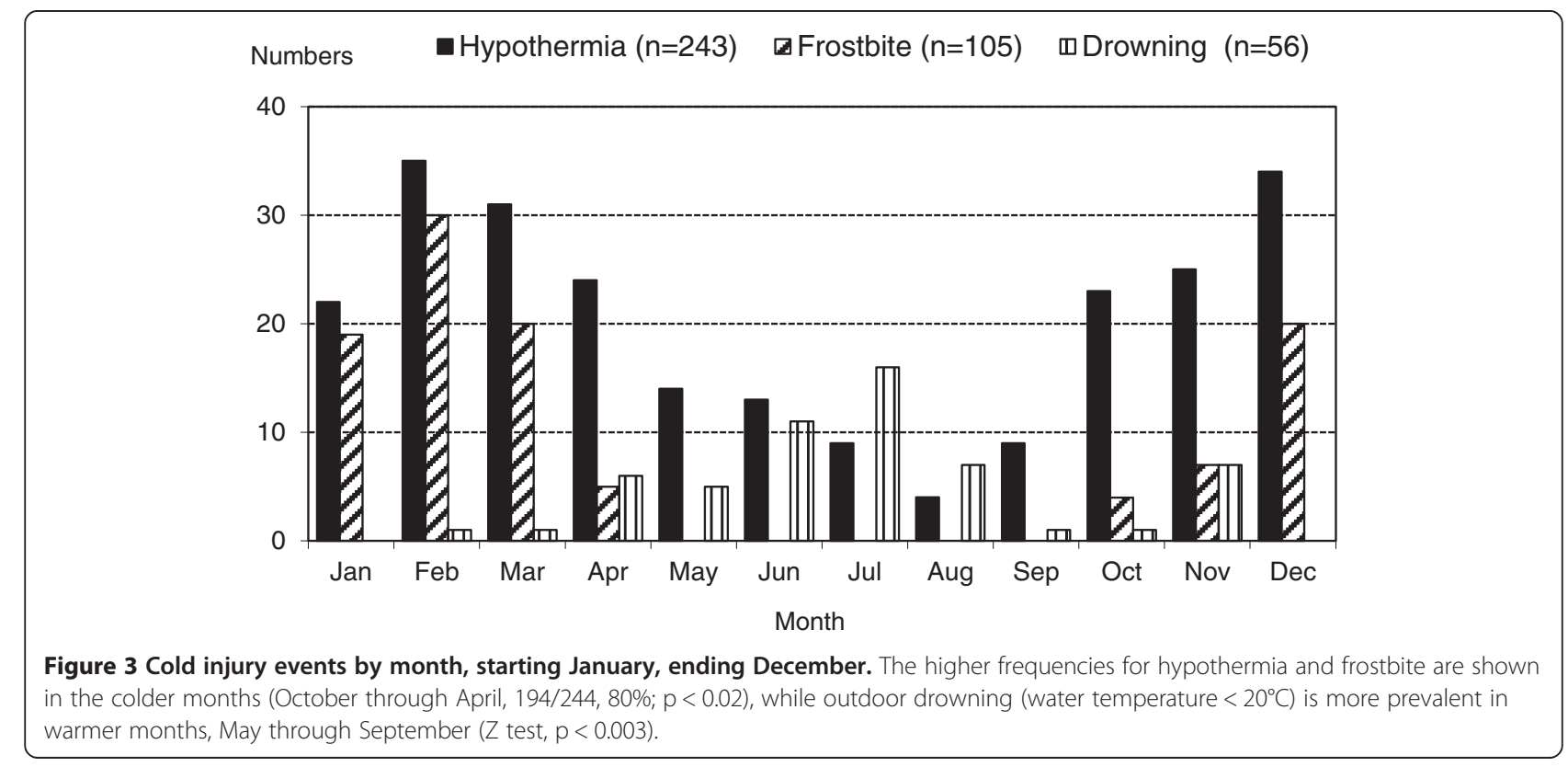


Table 2 Site for accidental cold injury

\begin{tabular}{lcccc}
\hline & $\mathbf{n}=$ & Indoor & Outdoor & $\begin{array}{c}\text { Location } \\
\text { not noted }\end{array}$ \\
\hline Hypothermia all & 244 & $22(9 \%)$ & $218(89 \%)$ & 4 \\
$\quad$ Mild $\left(34.9-32^{\circ} \mathrm{C}\right)$ & 154 & $11(7 \%)$ & $140(91 \%)$ & 3 \\
$\quad$ Moderate $\left(28.0-31.9^{\circ} \mathrm{C}\right)$ & 55 & $8(15 \%)$ & $46(84 \%)$ & 1 \\
$\quad$ Severe $\left(<28.0^{\circ} \mathrm{C}\right)$ & 29 & $3(10 \%)$ & $26(90 \%)$ & \\
Frostbite & 105 & $4(4 \%)$ & $95(90 \%)$ & 6 \\
Cold water drowning & 56 & 0 & $56(100 \%)$ & 2 \\
\hline
\end{tabular}

possible to determine if cold related injury incidences are changing, but a higher incidence of hypothermia than reported elsewhere suggests that it is possible.

Concerning pre-injury activities, the majority of victims had no specific activity identified in their patient journal. Possible explanations include that some of these victims were intoxicated (approximately $40 \%$ of total cases). Intoxication impairs the ability of an individual to assess and judge risks. It is also well recognized that many individuals combine intoxication with leisure outdoor activities such as snowmobile driving or fishing.

For a small subset of patients admitted with the diagnosis hypothermia, the only recorded temperature measurement was one that was over $35^{\circ} \mathrm{C}$. There are several possible interpretations of this finding. One is that the clinicians simply failed to record a lower measured temperature. Another is that they measured a body core temperature correctly and the temperature was actually above $35^{\circ} \mathrm{C}$ at hospital admission. These types of patients, with mild cold injury are probably quite common, even though they usually are not identified with a formal hypothermia diagnosis in the national patient diagnosis registry.

A large portion of the hypothermia victims were diagnosed presumptively at the accident site, though a core temperature measurement was not recorded for this in the hospital records. One possible explanation of this is that the personnel had an opportunity to measure temperature, but did not prioritize doing this (and recording their measurements). Another possible explanation is that they did not have the means to measure core temperature. Once in the hospital, temperature was measured more systematically, although it was infrequently recorded which body area, and with which device. The optimal way to measure core temperature is in the esophagus, and this can be performed even in awake patients [29,30]. Other minimally invasive means of assessing include urinary bladder (catheter) probes, or rectally. Measuring temperature in the ear by infrared methods is widely regarded as inaccurate, though a closed ear canal temperature measurement performed correctly is considered reliable even in a cold environment [31]. It is important that both site and time of measurement are recorded [32] so that a time course of rewarming can be reviewed and assessed. Furthermore, documentation in the hospital record according to an international standard for on-site evaluation and treatment, including level of consciousness and presence or absence of shivering, along with field treatment should be performed [33,34].

External, non-invasive warming methods such as forced-air warming have become a favored method, even for moderate and severe hypothermia victims [35-37]. Other more invasive rewarming methods persist, though in these observations at a very low incidence. There were very few cardiac arrest and extracorporeal rewarming events observed in this cohort. This may be due to very long transport distances to a single centralized thoracic surgery resource for the whole region. There is no clear evidence in our findings to suggest that less invasive methods are less effective.

Limitations of this retrospective chart review study design include primarily the risk for not being able to identify and collect all the relevant patient information from the four phases of care for cold injury victims. While ambulance and hospital records were reviewed, it is possible that not all relevant information was recorded in these journals, or that in the paper chart review process, some relevant information was recorded but not identified and abstracted. There were clear limitations concerning

Table 3 Electrocardiographic findings

\begin{tabular}{|c|c|c|c|c|c|c|}
\hline & $\mathrm{n}=$ & ECG taken & ECG-AF & ECG-VES & ECG-VT & ECG-VF \\
\hline Hypothermia & 244 & $104 / 244$ & 19/104 & $4 / 104$ & $1 / 104$ & $2 / 104$ \\
\hline Mild $\left(34.9-32^{\circ} \mathrm{C}\right)$ & 154 & $65 / 154$ & $9 / 65$ & $3 / 65$ & $0 / 65$ & $0 / 65$ \\
\hline Moderate $\left(28.0-31.9^{\circ} \mathrm{C}\right)$ & 55 & $22 / 55$ & $5 / 22$ & $0 / 22$ & $0 / 22$ & $0 / 22$ \\
\hline Severe $\left(<28.0^{\circ} \mathrm{C}\right)$ & 29 & $17 / 29$ & $5 / 17$ & $1 / 17$ & $2 / 17$ & $2 / 17$ \\
\hline Missing data & 6 & & & & & \\
\hline Frostbite & 105 & $25 / 105$ & $8 / 25$ & $0 / 25$ & $0 / 25$ & $0 / 25$ \\
\hline Cold water drowing & 56 & $21 / 56$ & $1 / 21$ & $2 / 21$ & $0 / 21$ & $0 / 21$ \\
\hline
\end{tabular}

Abbreviations: $E C G$ electrocardiogram, $A F$ atrial fibrillation, $V E S$ frequent ventricular extrasystoles, $V T$ ventricular tachycardia, $V F$ ventricular fibrillation. 
Table 4 Pre-injury activities, comorbidities, and cofactors

\begin{tabular}{|c|c|c|c|}
\hline All results in $\%$ & Hypothermia & Frostbite & Drowning \\
\hline \multicolumn{4}{|l|}{ Activities } \\
\hline Car/driving & 2 & 2 & 2 \\
\hline Snowmobile & 5 & 9 & 4 \\
\hline Walking & 5 & 20 & 0 \\
\hline Skiing & 1 & 2 & 2 \\
\hline Mountain climbing & 0 & 4 & 0 \\
\hline Fishing & 3 & 0 & 2 \\
\hline Falling through ice & 9 & 4 & 21 \\
\hline Outdoor skating & 1 & 0 & 2 \\
\hline Not recorded & 74 & 59 & 67 \\
\hline \multicolumn{4}{|l|}{ Co-morbidities } \\
\hline Ischemic heart disease & 20 & 10 & 5 \\
\hline Cerebrovascular disease & 7 & 7 & 5 \\
\hline Multiple trauma & 5 & 5 & 2 \\
\hline Psychiatric illness & 7 & 14 & 2 \\
\hline Dementia & 9 & 9 & 0 \\
\hline Epilepsy & 2 & 0 & 4 \\
\hline $\begin{array}{l}\text { Suicide attempts/apparent } \\
\text { suicide }\end{array}$ & 4 & 2 & 2 \\
\hline \multicolumn{4}{|l|}{ Co-factors } \\
\hline Ethanol & 34 & 28 & 30 \\
\hline Opiate & 1 & 0 & 0 \\
\hline Benzodiazepine & 5 & 5 & 4 \\
\hline Anti-depressive & 1 & 1 & 0 \\
\hline Amphetamine & 2 & 5 & 0 \\
\hline
\end{tabular}

documentation of measurement of core temperature, and the time course of rewarming. Also, this type of relatively small sample size with retrospective analysis cannot be used to make precise estimates of risk. Prospective structured data collection and a formalized effective data capture in a registry will be needed in order to allow more

Table 5 Method of rewarming

\begin{tabular}{lcccc}
\hline & & \multicolumn{3}{c}{ Hypothermia severity } \\
\cline { 3 - 5 } & Hypothermia all & Mild & Moderate & Severe \\
\hline Forced air warming & 244 & 154 & 55 & 29 \\
Warm bath & 167 & 94 & 50 & 23 \\
Warmed infusion & 3 & 1 & 0 & 2 \\
Extracorporeal & 112 & 66 & 26 & 20 \\
Water-filled garment & 1 & 0 & 0 & 1 \\
Periotoneal dialys & 3 & 0 & 1 & 2 \\
Radiant warming & 1 & 0 & 0 & 1 \\
Passive rewarming & 6 & 5 & 0 & 1 \\
\hline
\end{tabular}

Table 6 Frostbite injuries

\begin{tabular}{lc}
\hline & $\mathbf{n}$ \\
\hline Depth of injury & \\
Deep & 65 \\
Superficial & 14 \\
Both & 24 \\
Not specified & 27 \\
\hline Location of injury & \\
One hand & 20 \\
Both hands & 33 \\
One foot & 18 \\
Both feet & 45 \\
Lower arm & 3 \\
Lower leg & 14 \\
Face & 4 \\
Thorax or abdomen & 3 \\
\hline
\end{tabular}

precise and less bias analysis of cold injury and associated or contributing factors.

\section{Conclusions}

The incidence of accidental hypothermia seems to be increasing in this studied sub-arctic region. Likely associated factors are recognized (ethanol intake, dementia, and psychiatric diagnosis). We have not been able to evaluate if the regional health care system that was examined has been optimally effective with treatment, since limitations in hospital patient documentation restricted analysis of this.

\section{Additional file}

Additional file 1: Data collection sheet.

\section{Competing interests}

There were no financial competing interests for any of the authors.

\section{Authors' contributions}

$\mathrm{HB}$ has participated in study design, data collection, data analysis, and manuscript writing. GJ has participated in study design, data analysis and manuscript writing. GG has participated in study design, data analysis and manuscript writing. KÄ has participated in study design, data analysis and manuscript writing. MF has participated in study design, data analysis and manuscript writing. All authors have read and approved the final manuscript.

\section{Acknowledgements}

The authors would like to thank Lena Algers, Marit Sarri, Lena Nilsson, and Marie Nordgren for help with data collection, and Marianne Ekström and Annika Kumlin for their work with data management. The authors would like to thank Ola Winsö for general support and assistance with the manuscript. The authors acknowledge funding support for this project from the County Council of Västerbotten and the University Hospital of Umeå, as well as Umeå University, all in Sweden. 


\section{Author details}

${ }^{1}$ Department of Surgical and Perioperative Sciences, Anesthesia and Intensive Care Medicine, Faculty of Medicine, Umeå University, S-901 85 Umeå, Sweden. ${ }^{2}$ Kinesiology and Recreation Management, and Anesthesia, University of Manitoba, Winnipeg, Canada. ${ }^{3}$ Emergency and Disaster Medicine Centre, Umeå University, S-901 85 Umeå, Sweden.

Received: 20 June 2013 Accepted: 20 January 2014

Published: 27 January 2014

\section{References}

1. Giesbrecht GG: Cold stress, near drowning and accidental hypothermia: A review. Aviat Space Environ Med 2000, 71:733-752

2. Brown DJ, Brugger H, Boyd J, Paal P: Accidental hypothermia. N Engl J Med 2012, 367(20):1930-8. Erratum in: N Engl J Med 2013, 368(4):394.

3. Epstein E, Anna K: Accidental hypothermia. BMJ 2006, 332(7543):706-9.

4. Biem J, Koehncke N, Classen D, Dosman J: Out of the cold: management of hypothermia and frostbite. CMAJ 2003, 168(3):305-11.

5. Disaster planning section, Swedish National Board of Health and Welfare: Hypothermia - Cold Injuries and Cold Water Near Drowning. 2002. http://www.socialstyrelsen.se/publikationer2002/2002-110-14, accessed December 3, 2013. ISBN ISBN: 91-7201-640-X

6. The Estonia disaster: The loss of M/S Estonia in the Baltic on 28th September 1994 - KAMEDO-report 68. Stockholm: Swedish Disaster Medicine Study Organisation at the National Board of Health and Welfare; 1997.

7. Swedish Disaster Medicine Study Organisation at the National Board of Health and Welfare: Sinking of the MS Sleipner on 26 November 1999 KAMEDO-report 77. Stockholm: Swedish Disaster Medicine Study Organisation at the National Board of Health and Welfare; 2003.

8. Silfvast T, Pettilä V: Outcome from severe accidental hypothermia in Southern Finland- a 10-year review. Resuscitation 2003, 59(3):285-90.

9. Bierens J: Accidental hypothermia: Incidence, risk factors and clinical course of patients admitted to hospital. Eur J Emerg Med 1995, 2:38.

10. DeGroot DW, Castellani JW, Williams JO, Amoroso PJ: Epidemiology of U.S Army cold weather injuries, 1980-1999. Aviat Space Environ Med 2003, 74(5):564-70.

11. Hall A, Evans K, Pribyl S: Cold injury in the United States military population: current trends and comparison with past conflicts. J Surg Educ 2010, 67(2):61-5.

12. Hwang SW, Lebow JM, Bierer MF, O'Connell JJ, Orav EJ, Brennan TA: Risk factors for death in homeless adults in Boston. Arch Intern Med 1998, 158(13):1454-60

13. Hislop LJ, Wyatt JP, McNaughton GW, Ireland AJ, Rainer TH, Olverman G, Laughton LM: Urban hypothermia in the west of Scotland. West of Scotland Accident and Emergency Trainees Research Group. BMJ 1995, 311(7007):725

14. Tanaka M, Tokudome S: Accidental hypothermia and death from cold in urban areas. Int J Biometeorol 1991, 34(4):242-6.

15. Danzl DF, Pozos RS, Auerbach PS, Glazer S, Goetz W, Johnson E, Jui J, Lilja P, Marx JA, Miller J: Multicenter hypothermia survey. Ann Emerg Med 1987 16(9):1042-55

16. Turk EE: Hypothermia. Forensic Sci Med Pathol 2010, 6(2):106-15

17. Brändström H, Eriksson A, Giesbrecht G, Angquist KA, Haney M: Fatal hypothermia: an analysis from a sub-arctic region. Int J Circumpolar Health 2012, 71:1-7.

18. World Health Organization: International Classification of Diseases (ICD-10) c2012 [http://www.who.int/classifications/icd/en/]

19. United States National Transportation Safety Board. 1998. http://www.ntsb. gov/news/events/2010/fishing_vessel/presentations/5-Hiscock-QFR-What-iscold-water.pdf Accessed November 30, 2013.

20. Deakin CD: Drowning: more hope for patients, less hope for guidelines. Resuscitation 2012, 83:1051-52.

21. Jolly BT, Ghezzi KT: Accidental hypothermia. Emerg Med Clin North Am 1992, 10(2):311-27.

22. Jurkovich GJ: Environmental cold-induced injury. Surg Clin North Am 2007, 87(1):247-67. viii.

23. Rubin DB: Matching to Remove Bias in Observational Studies. Biometrics 1973, 29(1):159-183.

24. Juopperi K, Hassi J, Ervasti O, Drebs A, Näyhä S: Incidence of frostbite and ambient temperature in Finland, 1986-1995. A national study based on hospital admissions. Int J Circumpolar Health 2002, 61(4):352-62.
25. Valnicek SB, Chasmar LR, Clapson JB: Frostbite in the prairies: A 12 year review. Plas Reconstruct Sur 1993, 92:633-641.

26. Mäkinen TM, Jokelainen J, Näyhä S, Laatikainen T, Jousilahti P, Hassi J: Occurrence of frostbite in the general population-work-related and individual factors. Scand J Work Environ Health 2009, 35(5):384-93.

27. Nordberg G, von Strauss E, Kareholt I, Johansson L, Wimo A: The amount of informal and formal care among non-demented and demented elderly persons-results from a Swedish population-based study. Int J Geriatr Psychiatry 2005, 20:862-71.

28. Jyrkkä J, Enlund H, Lavikainen P, Sulkava R, Hartikainen S: Association of polypharmacy with nutritional status, functional ability and cognitive capacity over a three-year period in an elderly population.

Pharmacoepidemiol Drug Saf 2011, 20:514-22.

29. Fulbrook P: Core temperature measurement: a comparison of rectal axillary and pulmonary artery blood temperature. Intensive Crit Care Nurs 1993, 9(4):217-25.

30. Fulbrook P: Core body temperature measurement: a comparison of axilla, tympanic membrane and pulmonary artery blood temperature. Intensive Crit Care Nurs 1997, 13(5):266-72.

31. Walpoth BH, Galdikas J, Leupi F, Muehlemann W, Schlaepfer P, Althaus U: Assessment of hypothermia with a new "tympanic" thermometer. J Clin Monit 1994, 10(2):91-6.

32. Soar J, Perkins GD, Abbas G, Alfonzo A, Barelli A, Bierens JJ, Brugger H, Deakin CD, Dunning J, Georgiou M, Handley AJ, Lockey DJ, Paal P, Sandroni C, Thies KC, Zideman DA, Nolan JP: European resuscitation council guidelines for resuscitation 2010 Section 8. Cardiac arrest in special circumstances: electrolyte abnormalities, poisoning, drowning, accidental hypothermia, hyperthermia, asthma, anaphylaxis, cardiac surgery, trauma, pregnancy, electrocution. Resuscitation 2010, 81(10):1400-33.

33. Durrer B, Brugger $H$, Syme D: The medical on-site treatment of hypothermia: ICAR-MEDCOM recommendation. International Commission for Mountain Emergency Medicine. High Alt Med Biol 2003, 4(1):99-103.

34. Danzl DF, Pozos RS: Accidental hypothermia. N Engl J Med 1994 331(26):1756-60

35. Deakin CD: Forced air surface rewarming in patients with severe accidental hypothermia. Resuscitation 2000, 43(3):223.

36. Kornberger E, Schwarz B, Lindner KH, Mair P: Forced air surface rewarming in patients with severe accidental hypothermia. Resuscitation 1999 41(2):105-11.

37. Röggla M, Frossard M, Wagner A, Holzer M, Bur A, Röggla G: Severe accidental hypothermia with or without hemodynamic instability: rewarming without the use of extracorporeal circulation. Wien Klin Wochenschr 2002, 114(8-9):315-20.

doi:10.1186/1757-7241-22-6

Cite this article as: Brändström et al: Accidental cold-related injury leading to hospitalization in northern Sweden: an eight-year retrospective analysis. Scandinavian Journal of Trauma, Resuscitation and Emergency Medicine 2014 22:6.

\section{Submit your next manuscript to BioMed Central and take full advantage of:}

- Convenient online submission

- Thorough peer review

- No space constraints or color figure charges

- Immediate publication on acceptance

- Inclusion in PubMed, CAS, Scopus and Google Scholar

- Research which is freely available for redistribution 